\title{
HEMANGIOSARCOMA IN A SOUTH AMERICAN SEA LION (OTARIA BYRONIA)
}

\author{
Mi-Hyeon You, D.V.M., Il-Hong Bae, D.V.M., Hyang Jee, D.V.M., Mi-Jin Yoo, D.V.M., \\ Nam-Shik Shin, D.V.M., Ph.D., and Dae-Yong Kim, D.V.M., Ph.D.
}

\begin{abstract}
A 10-yr-old male South American sea lion (Otaria byronia) died after several weeks of depression, anorexia, weight loss, and progressive respiratory distress. At necropsy, three confluent, lobulated, dark-red masses were noted in the mesentery. Similar masses were also observed in the lung and both kidneys. Hemangiosarcoma was diagnosed based on gross findings, histopathology, and immunohistochemistry. This is the first case of hemangiosarcoma reported in pinnipeds.

Key words: Hemangiosarcoma, Otaria byronia, sea lion, tumor, immunohistochemistry.
\end{abstract}

\section{BRIEF COMMUNICATION}

Hemangiosarcoma is an aggressive tumor of the vascular endothelium that carries a poor prognosis. ${ }^{6,12}$ It commonly affects multiple internal organs concurrently or in one cutaneous site. ${ }^{6,12}$ There is controversy regarding whether the multiorgan presentation represents multiple independent neoplasms or metastases from a primary site. Rupture of the tumor can lead to internal bleeding, followed by hypovolemic shock and organ failure. ${ }^{7}$ A paraneoplastic syndrome includes anemia and thrombocytopenia. ${ }^{7}$ Although most common in dogs and cats, it is rarely reported in other domestic and zoo animals. ${ }^{6,12}$

In sea lions, only a few cases of spontaneous neoplasia have been reported, and most of these cases occurred in stranded California sea lions. ${ }^{9}$ This report describes a multiorgan presentation of hemangiosarcoma in a South American sea lion (Otaria byronia).

A 10-yr-old male sea lion was housed in an outdoor exhibit at the Seoul Grand Park in South Korea and died after several weeks of depression, anorexia, weight loss, and progressive respiratory distress. Shortly after death, the sea lion was admitted to the Department of Pathology, College of Veterinary Medicine, Seoul National University (South Korea) for a postmortem examination. At necropsy, the carcass was emaciated. The abdominal and thoracic cavities each contained about $1,000 \mathrm{ml}$ of unclotted red-tinged thick fluid. Three confluent, dark-

From the Laboratory of Veterinary Pathology, College of Veterinary Medicine, Seoul National University, Seoul 151-742, Korea (You, Bae, Jee, Kim); the Laboratory of Veterinary Wildlife Diseases, College of Veterinary Medicine, Seoul National University, Seoul 151-742, Korea (Shin); and Seoul Grand Park, Kwachun, Korea (Yoo). Correspondence should be directed to Dr. Kim (daeyong@ snu.ac.kr). red, lobulated masses of approximately $5 \mathrm{~cm}$ in diameter were present in the mesentery, between the duodenum and the colon (Fig. 1). Cut surfaces revealed multiple areas of hemorrhage and necrosis. The lung and both kidneys had multiple soft, tancolored, blood-filled masses measuring $1-3 \mathrm{~cm}$ in diameter. Representative tissue samples were fixed in $10 \%$ neutral phosphate-buffered formalin, routinely processed, embedded in paraffin, sectioned at $3 \mu \mathrm{m}$, and stained with hematoxylin and eosin for light microscopic examination.

The masses from the mesentery, lungs, and both kidneys had similar histologic features consisting of nonencapsulated, partially infiltrative, pleomorphic cells, primarily polygonal to spindle shaped, lining erythrocyte-filled clefts or channels, with intervening hyaline eosinophilic material (Fig. 2). Neoplastic cells had distinct borders, a scant to moderate amount of eosinophilic cytoplasm, and an irregular, flat to oval hyperchromatic nucleus with inconspicuous nucleoli and two to four mitotic figures per high-power field $(\times 400)$. Large areas of necrosis and hemorrhage, intermingled with cholesterol clefts and hematoidin depositions, were present. In order to determine the cellular origin of the neoplastic cells, immunohistochemistry was performed using Factor AIII (Dako, Carpinteria, California 93013, USA) as primary antibody at a dilution of $1: 100$. Immunoreactivity was detected by the standard avidin-biotin immunoperoxidase method (ABC Elite Kit, Dako, Carpinteria, California 93013, USA). Canine renal hemangiosarcoma and diluent without primary antibody were used as positive and negative controls, respectively. Approximately $40 \%$ of the neoplastic cells were strongly positive for Factor VIII antigen (Fig. 2, inset). Thus, based on the presence of vasculature lined with anaplastic, plump endothelial cells of varying size and Factor VIII staining, a diagnosis of hemangiosarcoma was made. 


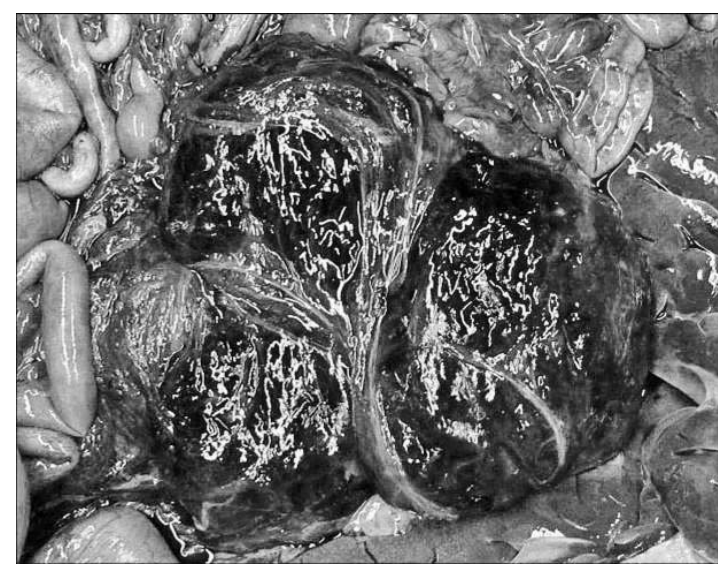

Figure 1. Note three soft, lobulated, dark-red mesenteric masses between the duodenum and colon in a 10yr-old male Otaria byronia.

In dogs, the spleen, heart, liver, lung, and skin are the most common sites of hemangiosarcomas, with the spleen, heart, and liver more often observed as part of a multicentric disease. The kidney and serosa of the urinary bladder are less frequent sites for hemangiosarcoma and are often solitary sites of involvement. ${ }^{6}$ In this sea lion, neoplastic masses were present in the mesentery, lungs, and both kidneys. These masses may represent multiple independent neoplasms or metastases from a primary site. It is possible that the kidney, although more frequently reported as a solitary site, or the mesentery, which was the largest mass in this case, could have been the primary site. The cause of death is uncertain, but two possibilities are most likely. The masses in the lungs did not occupy enough surface area to directly compromise respiratory function and thus to explain the progressive respiratory distress noted clinically. Thus, the progressive clinical deterioration may indicate the presence of progressive anemia, perhaps confounded by thrombocytopenia as a paraneoplastic syndrome of hemangisarcoma. ${ }^{7}$ Antemortem blood analysis was not performed to support or refute this possibility. A second, and not mutually exclusive, possibility was shock following rupture of the masses, as indicated by the bicavitary hemorrhage noted on postmortem examination. Analysis of the effusion would be necessary to confirm that it was not serosanguineous effusion, especially as foci of rupture in the masses were not found on necropsy. Additionally, this hemorrhage may have occurred during postmortem handling of the animal, because the blood was not clotted. However, should the an-

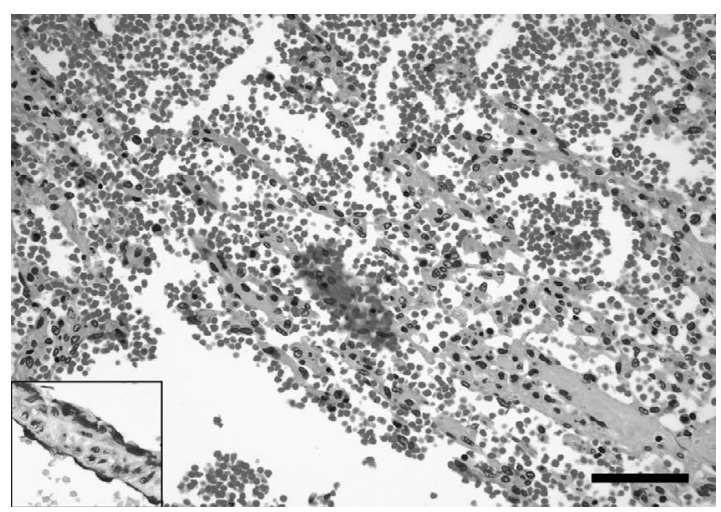

Figure 2. Photomicrograph of the mesenteric masses of a 10-yr-old male Otaria byronia, showing pleomorphic, mainly polygonal to spindle, cells lining erythrocyte-filled clefts or channels. Hematoxylin and eosin (H\&E) stain. Bar $=100 \mu \mathrm{m}$. Inset. Note neoplastic cells positive to factor VIII, avidin-biotin immunoperoxidase method.

imal have been thrombocytopenic, then the blood may not have been able to clot antemortem.

The etiology of naturally occurring hemangiosarcoma in animals and humans is unknown. German shepherds, golden retrievers, and Labrador retrievers are overrepresented in many case series. ${ }^{3,10,11}$ Beagles exposed to ionizing radiation preor postnatally have a documented increase in hemangiosarcoma. ${ }^{1}$ Cutaneous hemangiosarcomas are found more frequently in dogs with minimal pigmentation and thin hair coats who are exposed to ultraviolet light. ${ }^{8}$ In humans, human immunodeficiency virus infection and exposure to a variety of chemicals, including arsenicals, vinyl chloride, and thorium dioxide, are associated with hemangiosarcoma development. ${ }^{5}$ In California sea lions, otarine herpesvirus- 1 is associated with endemic genital tumors, ${ }^{4}$ and organochlorines are related to cancerassociated mortality in the same species. ${ }^{13}$ The cause of hemangiosarcoma in this South American sea lion remains unknown.

Hemangiosarcomas rarely have been reported in zoo and wild mammals, with a case in an eastern barred bandicoot (Perameles gunnii), and they have not been reported previously in pinnipeds. ${ }^{2}$ As a result of the condition's biologic aggressiveness, the prognosis for all species of animals with hemangiosarcoma remains poor. This case is presented to contribute to our understanding of the prevalence and biological behavior of hemangiosarcomas in sea lions.

\section{LITERATURE CITED}

1. Benjamin, S. A., A. C. Lee, G. M. Angleton, W. J. Saunders, T. J. Keefe, and C. H. Mallinckrodt. 1998. Mor- 
tality in beagles irradiated during prenatal and postnatal development. II. Contribution of benign and malignant neoplasia. Radiat. Res. 150: 330-348.

2. Bodley, K. B., R. J. Booth, J. Samuel, and J. S. Wilkie. 2000. Disseminated haemangiosarcoma in an eastern barred bandicoot (Perameles gunnii). Aust. Vet. J. 75: 605-607.

3. Brown, N. O., A. K. Patnaik, and E. G. MacEwen. 1985. Canine hemangiosarcoma: retrospective analysis of 104 cases. J. Am. Vet. Med. Assoc. 186: 56-58.

4. Buckles, E. L., L. J. Lowenstine, C. Funke, R. K. Vittore, H. N. Wong, J. A. St. Leger, D. J. Greig, R. S. Duerr, F. M. Gulland, and J. L. Scott. 2006. Otarine herpesvirus-1, not papillomavirus, is associated with endemic tumors in California sea lions (Zalophus californianus). J. Comp. Pathol. 135: 183-189.

5. Falk, H., J. Herbert, S. Crowley, K. G. Ishak, L. B. Thomas, H. Popper, and G. G. Caldwell. 1981. Epidemiology of hepatic angiosarcoma in the United States: 19641974. Environ. Health Perspect. 41: 107-113.

6. Goldschmidt, M. H., and M. J. Hendrick. 2002. Tumors of the skin and soft tissues. In: Meuten, D. J. (ed.). Tumors in Domestic Animals, 4th ed. Iowa State Univ. Press, Ames, Iowa. Pp. 99-101.

7. Hargis, A. M., and B. F. Feldman. 1991. Evaluation of hemostatic defects secondary to vascular tumors in dogs: 11 cases (1983-1988). J. Am. Vet. Med. Assoc. 198: 891-894.

8. Hargis, A. M., P. J. Ihrke, W. L. Spangler, and A. A. Stannard. 1992. A retrospective clinicopathologic study of 212 dogs with cutaneous hemangiomas and hemangiosarcomas. Vet. Pathol. 29: 316-328.

9. Newman, S. J., and S. A. Smith. 2006. Marine mammal neoplasia: a review. Vet. Pathol. 43: 865-880.

10. Schultheiss, P. C. 2004. A retrospective study of visceral and nonvisceral hemangiosarcoma and hemangiomas in domestic animals. J. Vet. Diagn. Invest. 16: 522526.

11. Srebernik, N., and E. C. Appleby. 1991. Breed prevalence and sites of haemangioma and haemangiosarcoma in dogs. Vet. Rec. 129: 408-409.

12. Thamm, D. H. 2007. Miscellaneous tumors. In: Withrow, S. T., and D. M. Vail (eds.). Withrow and MacEwen's Small Animal Clinical Oncology, 4th ed. Saunders, St. Louis, Missouri. Pp. 785-795.

13. Ylitalo, G. M., J. E. Stein, T. Hom, L. L. Johnson, K. L. Tilbury, A. J. Hall, T. Rowles, D. Greig, L. J. Lowenstine, and F. M. Gulland. 2005. The role of organochlorines in cancer-associated mortality in California sea lions (Zalophus californianus). Mar. Pollut. Bull. 50: 30-39.

Received for publication 3 May 2007 